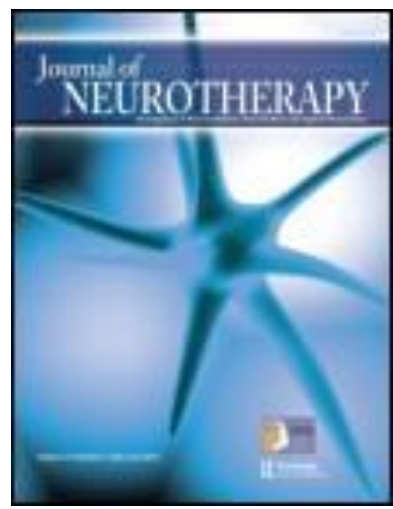

Journal of Neurotherapy: Investigations in Neuromodulation, Neurofeedback and Applied Neuroscience

\title{
The Effects of Humorous Literature on Emotion: A Pilot Project Comparing Children with Asperger's Syndrome Before and After Neurofeedback Training and Controls
}

\author{
Maureen T. B. Drysdale ${ }^{a}$, Yvonne J. Martinez ${ }^{b}$ \& Lynda Thompson ${ }^{c}$ \\ a Department of Psychology , St. Jerome's University/University of Waterloo, Waterloo , \\ Ontario , Canada \\ ${ }^{\mathrm{b}}$ Department of Psychology, University of Waterloo, Waterloo, Ontario , Canada \\ c The ADD Centre and The Biofeedback Institute of Toronto, Toronto, Ontario, Canada \\ Published online: 21 Aug 2012.
}

To cite this article: Maureen T. B. Drysdale , Yvonne J. Martinez \& Lynda Thompson (2012) The Effects of Humorous Literature on Emotion: A Pilot Project Comparing Children with Asperger's Syndrome Before and After Neurofeedback Training and Controls, Journal of Neurotherapy: Investigations in Neuromodulation, Neurofeedback and Applied Neuroscience, 16:3, 196-209, DOI: $10.1080 / 10874208.2012 .705758$

To link to this article: http://dx.doi.org/10.1080/10874208.2012.705758

\section{PLEASE SCROLL DOWN FOR ARTICLE}

(c) International Society for Neurofeedback and Research (ISNR), all rights reserved. This article (the "Article") may be accessed online from ISNR at no charge. The Article may be viewed online, stored in electronic or physical form, or archived for research, teaching, and private study purposes. The Article may be archived in public libraries or university libraries at the direction of said public library or university library. Any other reproduction of the Article for redistribution, sale, resale, loan, sublicensing, systematic supply, or other distribution, including both physical and electronic reproduction for such purposes, is expressly forbidden. Preparing or reproducing derivative works of this article is expressly forbidden. ISNR makes no representation or warranty as to the accuracy or completeness of any content in the Article. From 1995 to 2013 the Journal of Neurotherapy was the official publication of ISNR (www. Isnr.org); on April 27, 2016 ISNR acquired the journal from Taylor \& Francis Group, LLC. In 2014, ISNR established its official open-access journal NeuroRegulation (ISSN: 2373-0587; www.neuroregulation.org).

THIS OPEN-ACCESS CONTENT MADE POSSIBLE BY THESE GENEROUS SPONSORS

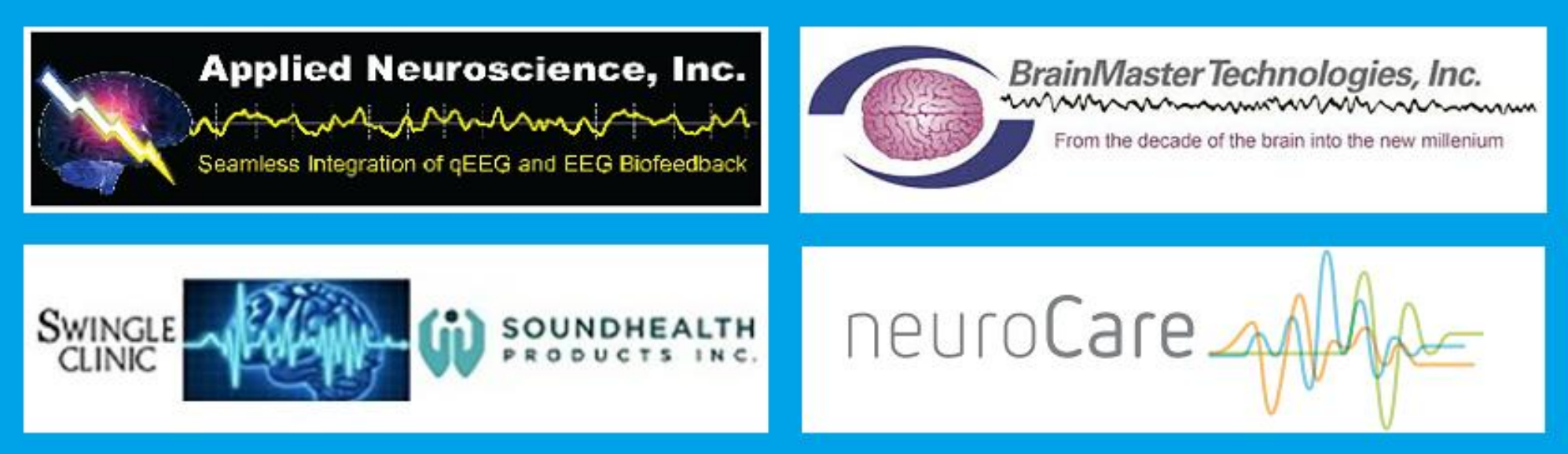




\title{
THE EFFECTS OF HUMOROUS LITERATURE ON EMOTION: A PILOT PROJECT COMPARING CHILDREN WITH ASPERGER'S SYNDROME BEFORE AND AFTER NEUROFEEDBACK TRAINING AND CONTROLS
}

\author{
Maureen T. B. Drysdale ${ }^{1}$, Yvonne J. Martinez ${ }^{2}$, Lynda Thompson ${ }^{3}$ \\ ${ }^{1}$ Department of Psychology, St. Jerome's University/University of Waterloo, Waterloo, \\ Ontario, Canada \\ ${ }^{2}$ Department of Psychology, University of Waterloo, Waterloo, Ontario, Canada \\ ${ }^{3}$ The ADD Centre and The Biofeedback Institute of Toronto, Toronto, Ontario, Canada
}

\begin{abstract}
This study examined neurofeedback training, reading humorous stories, and emotion in children diagnosed with Asperger's Syndrome (AS). In a pre-posttest design (before and after the story), positive and negative affect were compared between controls and two experimental groups of children with AS - those beginning training $(<4$ sessions) and those near completion of training ( $>40$ sessions). Children with AS who had more than 40 sessions of neurofeedback responded the same way to the reading materials as the normally functioning controls with increases in positive affect and decreases in negative affect. Children with AS with less than 4 sessions of neurofeedback did not display this change.
\end{abstract}

\section{INTRODUCTION}

Asperger's Syndrome (AS) is recognized as a separate and distinct disorder classified under Pervasive Developmental Disorders in the Diagnostic and Statistical Manual of Mental Disorders (4th ed., text rev. [DSM-IV-TR]; American Psychiatric Association [APA], 2000). Hans Asperger was the first to describe the symptoms for AS - calling the condition "autistic psychopathy" — using terms like "little professors" and "socially isolated" (Asperger, 1944, 1991). In 1981, autism expert Lorna Wing coined the term "Asperger's Syndrome" after studying and writing about the unique symptoms she had observed in her case studies. However, it was not until 1992 that the disorder became official when it was listed in the World Health Organization's International Classification of Diseases (World Health Organization, 1994). In 1994, it was included in the DSM (4th ed.; APA, 1994).

Unlike autism and other developmental disorders, AS is not described by any significant adaptive behavior delays, language delays, or cognitive impairments (APA, 2000). In fact, children with AS typically have normal to superior cognitive and language development and have been found to have superior verbal skills compared to typically developing children (APA, 2000; Carpenter, Pennington, \& Rogers, 2001; Gepner, Deruelle, \& Grynfeltt, 2001; Mayes \& Calhoun, 2008; Rosenn, 1999; Smith Myles et al., 2002; Smith Myles \& Simpson, 2001; Thompson \& Thompson, 1998).

Received 15 March 2012; accepted 8 June 2012.

We express our gratitude to the staff at the ADD Centre and Biofeedback Institute of Toronto, Ontario, for their support and help with this study. We also thank the children at the Centre for participating and to their families for permitting participation. Finally, we extend our gratitude to the students who participated in the control group and to their teachers for taking the time out of their busy schedules to allow us into their classrooms. Authors are listed in alphabetical order in recognition of their equal scholarly contributions to this work. This article is based on an undergraduate honors thesis completed by Y. Martinez at the University of Waterloo, under the direct supervision of M. Drysdale.

Address correspondence to Maureen T. B. Drysdale, PhD, Department of Psychology, School of Public Health and Health Systems, St. Jerome's University/University of Waterloo, 290 Westmount Road, Waterloo, ON N2L 3G3, Canada. E-mail: mdrysdal@uwaterloo.ca 
On the other hand, AS shares several characteristics with autism. For example, it is characterized by deficiencies in social interactions (e.g., reciprocal communication, social understanding; Attwood, 1998), emotion regulation (Thompson \& Thompson, 2007), and affective communication, as well as by repetitive stereotyped behaviors (e.g., idiosyncratic interests, rigid routines; APA, 1994; Wing, 2001). Children with AS have been found to have difficulty understanding different types of literary techniques (i.e., metaphors, puns), understanding humor (Kaland et al., 2005; Thompson, Thompson, \& Reid, 2010), interpreting the emotional states of others, and/or inferring a character's state of mind (theory of mind; Attwood, 1998). Not surprising, these individuals often struggle with establishing meaningful, close relationships (Attwood, 1998).

Current prevalence estimates range from 0.3 to 71 per 10,000 (Ehlers \& Gillberg, 1993; Fombonne \& Tidmarsh, 2003). For school-age children, the rates are estimated to be 36 per 10,000 (Attwood, 1997) with a $4: 1$ ratio of boys to girls diagnosed (Ehlers \& Gillberg, 1993). Researchers explain that there is such discrepancy in the prevalence estimates because of the controversial issues regarding the diagnostic criteria used for AS - in particular, distinguishing it from high-functioning autism (Knezevic, Thompson, \& Thompson, 2010). Further confusion exists because these individuals show cognitive and academic abilities within the normal range of functioning (Mayes \& Calhoun, 2008).

Children with AS - because of their normal cognitive and academic abilities - are most likely integrated into the schools with their same-age, normally functioning peers. However, it has been argued that they struggle with fitting in (Portway \& Johnson, 2005) because of their deficits with social-emotional processing and awkward interpersonal skills (Kaland et al., 2005; Laurent \& Rubin, 2004). These children have difficulty understanding social stories, conversations, and narrativesespecially those involving figures of speech, sarcasm, humor, and irony (Kaland et al., 2005). They struggle with boundaries, as well as understanding and expressing their emotions (Laurent \& Rubin, 2004). As a result, they tend to be rejected and teased by their peers (Thompson \& Thompson, 2007). This is especially problematic when they transition to adolescence-a time when peer acceptance and friendships become increasingly salient (Durkin, 1995) and are significantly related to adjustment in school (Connell \& Wellborn, 1991), social functioning (Nangle \& Erdley, 2001), feelings of inclusion (Erdley, Nangle, Newman, \& Carpenter, 2001), self-worth (Connell \& Wellborn, 1991; Erdley et al., 2001; Rubin et al., 2004), and overall psychological well-being (Oberle, Schonert-Reichl, \& Thompson, 2010; Wentzel, 2009). Not surprisingly, many adolescents with AS perceive social relations as one of the most difficult aspects of their lives (Carrington, Paoinczak, \& Templeton, 2003) and often socially withdraw as a result (Thompson \& Thompson, 2007). Given findings linking social relations with negative mood in children and adolescents with AS (Hedley \& Young, 2006), many are at risk for mood disorders such as depression. In fact, research has indicated that adolescents with AS display higher levels of depressive symptoms than the general population (Ghaziuddin, Weidmer-Mikhail, \& Ghaziuddin, 1998).

With this in mind, it is imperative to find ways to alleviate the negative symptoms and effects of AS, including negative affect. Commonly tried interventions for AS include behavior therapy, social skills training, psychotherapy, and medications (e.g., SSRIs for anxiety and methylphenidate for hyperactivity; Green et al., 2006). However, Thompson and Thompson (2007) argued that outcome data are lacking and treatments using medications are often not favorable and can actually worsen or induce certain symptoms such as anxiety (i.e., an iatrogenic effect). More recently, favorable outcomes have been reported using neurofeedback (NFB) as a treatment for AS (Coben, 2007; Coben \& Myers, 2010; Knezenic et al., 2010; Kouijzer, van Schie, de Moor, Gerrits, \& Buitelaar, 2010; Thompson et al., 2010). 


\section{NFB TRAINING}

NFB - also called EEG biofeedback - is a treatment designed to target neurologically based conditions by altering the electrical activity of the brain (Lubar, 1995). The argument is that altering and normalizing brainwave (EEG) activity improves some the symptoms of AS (Reid, 2005). Researchers in the field of psychophysiology identify five types of brainwaves (EEG bands) - delta, theta, alpha, beta, and gamma - that become activated according to level of awareness (Hammond, 2011). Delta waves are the slowest $(.5-3.5 \mathrm{~Hz})$ and represent the lowest level of awareness (i.e., sleeping). With increasing awareness, brainwaves move from delta to theta $(4-8 \mathrm{~Hz}$; daydreaming) to alpha $(8-12 \mathrm{~Hz}$; disengaged and relaxed) to beta $(12-30 \mathrm{~Hz}$; alert intellectual activity) to gamma $(>30 \mathrm{~Hz}$; intense information processing; Hammond, 2011). Activity in the lower end $(12-15 \mathrm{~Hz})$ of the beta waves - measured across the sensorimotor strip (International 10-20 placement sites known as $\mathrm{C} 3, \mathrm{Cz}$, and $\mathrm{C} 4$ ) - is referred to as the sensorimotor rhythm (SMR) and is characterized by relaxed alertness (Hammond, 2011).

The goal of NFB training is to increase SMR and beta waves (i.e., the fast waves associated with relaxation and thinking, respectively) while decreasing theta and alpha waves (i.e., the slow waves associated with tuning out and daydreaming, respectively).

Increasingly, researchers have investigated the use of NFB training in treating individuals with anxiety disorders (Hammond, 2005), insomnia (Hammer, Colbert, Brown, \& Ilioi, 2011), depression (Choi, et al., 2011), attention deficit/hyperactivity disorder (deBeus \& Kaiser, 2011; deNiet, 2011; Levesque, Beauregard, \& Mensour, 2006; Lubar, 1995), learning disabilities (Thornton \& Carmody, 2005; Walker \& Norman, 2006) as well as being used to facilitate peak performance in normally functioning individuals (Kleber, Gruzelier, Bensch, \& Birbaumer, 2008). Positive gains have also been documented for individuals with AS (Coben \& Myers, 2010; Knezevic et al., 2010; Kouijzer et al., 2010; Thompson et al., 2010). More specifically, Thompson et al. (2010) reported significantly marked improvements in attention (both auditory and visual) and impulsivity. Coben and Myers (2010) reported significant improvements with social interaction and communication. With documented improvements across all areas of difficulty, there is increased potential for longterm management of the disorder.

\section{TEXT-BASED MATERIALS AND AFFECT}

As previously discussed, individuals with AS are more likely to develop depression than normally functioning individuals (Ghaziuddin et al., 1998) and although NFB has shown promise in the treatment of depression, individuals with AS - similar to normally functioning individuals who suffer occasional negative affect-need day-to-day strategies that can enhance mood during difficult times (e.g., at school). One strategy not previously examined for low affect in AS individuals is literature or text-based materials.

The use of reading materials to evoke positive (or negative) emotions is guided by a few theoretical models: the negative state relief model (Mitchell, Brown, Morris-Villagran, \& Villagran, 2001), the resource allocation model of mood effects (Riesberg, 1997), and the selective learning and recall model (moodincongruent and congruent learning; Bower, Gilligan, \& Monteiro, 1981; Ellis, Ottaway, Varner, Becker, \& Moore, 1997). Previous research has found that happy reading materials (such as therapeutic stories) are as effective in reducing negative affect as psychoeducational interventions (Parker, 2004). Thus, it is a possibility that the use of reading materials may also be used to help children with AS. Overall, studies have not investigated whether or not children diagnosed with AS can understand emotions in reading where there is an absence of pictures and/or drawings. It is unknown whether children with AS have difficulty understanding emotions in text-based materials. What is known is that children with autism can learn to recognize emotions 
(e.g., happy, sad, angry, scared) through social story intervention. However, it is not known if the recognition evokes a change in their affect.

Examining the impact of reading materials on affect among children diagnosed with AS is not without its challenges. For example, a problem with presenting humorous stories to children with AS is their difficulty with inferring beliefs and another person's state of mind (Theory of Mind), understanding different types of literary techniques (i.e., metaphors, puns), and recognizing humor (Kaland et al., 2005). Essentially, it is not clear whether children with AS have difficulty interpreting implied and literal meanings of text and/or lack understanding of affect and empathy (Attwood, 1998). Children with AS may have difficulty interpreting the emotional states of others (i.e., characters in the story) and/or inferring a character's state of mind and/or false beliefs (Attwood, 1998). Given these difficulties, it is quite possible that the emotions of children with AS will not be affected by humorous stories in the same way as what has been found with typically developing children.

Children with AS also experience difficulties in pragmatics (how language is used in social contexts), semantics (recognizing there are several meanings to words), and prosody (tone, stress of words in a sentence, pitch, and rhythm). Semantics is a particular area of concern when reading, because children with AS are usually unaware that there are multiple meanings, hidden meanings, metaphors, idioms, and puns used in literature (i.e., "keep your eye on the ball," "he was green with envy," "get lost"; Kaland et al., 2005). Therefore, this would severely affect their understanding and comprehension of a story. Given the impairments associated with AS, these children might find humorous stories difficult to follow and may have difficulty understanding the purpose and/or implications of humor.

Finally, complex literary skills may be weak with children in general; therefore, children with AS may not differ in their performance as compared to typically developing children. However, given that children with AS have not been found to have deficits in cognitive and language developments, we can assume that their reading and comprehension of text will be similar to that of typically developing children of the same age.

Given these difficulties, it is quite possible that emotional states of children with AS will not be affected by humorous stories in the same way as what has been found with typically developing children. Of interest, however, is whether or not NFB training has an effect on the ability to understand emotions in literature-especially happiness and humor-and if so, could this literature improve affect in children diagnosed with AS?

The goal of this study was to investigate the relationship between NFB training, reading happy stories, and affect in children diagnosed with AS. Specifically, in a pre- and posttest design (before and after reading a humorous story), affect was compared between controls and two experimental groups of children diagnosed with AS (those just beginning their NFB training and those who were near completion of NFB training). We were interested in whether children with AS who were just beginning their training would differ in posttesting affect scores compared to children who were almost finished with the NFB training and normally functioning controls. We were also interested in whether the children near NFB training completion would show changes in their affect at posttesting that were similar to the normally functioning controls.

Based on past research, we predicted that all children would understand the humorous stories selected. We also predicted that children in the control group and children near NFB training completion would show an increase in positive affect and a decrease in negative affect after reading the humorous story. However, children without NFB training would not show changes in positive or negative affect after reading a humorous story. The findings from this study will contribute to the literature concerning the use of NFB as a possible intervention in treating children with AS, particularly helping children with AS to better understand and recognize humor in text-based materials and improve affect. 


\section{METHODS}

\section{Participants}

Data collected from 37 children ranging from 10 to 14 years of age were used for this study. This particular age range was chosen because the selected humorous stories contained content and literary techniques appropriate for this age group and relevant for this type of study (i.e., for examining postreading affect). There were 14 children diagnosed with AS recruited from the ADD Centre/Biofeedback Institute of Toronto and 23 normally functioning controls (Group A) drawn from a local elementary school. The clinic from which the children with AS were recruited provides clinical assessments and NFB training for individuals with a range of mental health issues (e.g., attention deficit/ hyperactivity disorder, anxiety, AS). All clients at the Centre receive a full clinical assessment prior to beginning NFB training. Children were selected for this study if they met the DSM-IVTR (APA, 2000) criteria for AS. Of the 14 children with AS in the final data set, 11 were near completion of their NFB training (i.e., $>40$ sessions; Group C) and three were just beginning their training (Group B). Children in Group B must not have received more than four sessions of NFB training at the time of testing. Children in Group $C$ must have received a minimum of 40 sessions of NFB training. Forty sessions is considered to be the average number of training sessions in which improvements in cognitive and behavioral functioning are observed (Thompson \& Thompson, 1998; Thompson et al., 2010). Fewer than four training sessions (i.e., beginning training) is not deemed significant by the clinicians at the Centre. Each training session lasts approximately 50 min, with 40 sessions typically taking 6 months to complete. Children who had received more than four sessions and up to 40 sessions of training were excluded from the study. Some children (preand post-NFB training) were receiving psychostimulants (e.g., Ritalin), antidepressants (e.g., Norpramin and Prozac), and/or antihypertensive medications (e.g., Clonidine) to control specific behaviors and/or emotions. Due to ethical considerations, the use of medications was permitted in this study by all children with AS.

The children in Group A consisted of normally functioning, typically developing children. Children were excluded from this control group if they had been previously diagnosed with a learning disability or psychopathology, and/or were receiving any form of intervention such as psychotherapy or counseling, and/or were taking any medication(s) to control behavior and/or emotions.

It is important to note that all efforts were made at the outset of the study to ensure an equal number of participants across the three groups of children. Unfortunately, the availability of children meeting the required number of training sessions, combined with an inability to understand the stories, resulted in small samples for both Groups B and C-with Group B having only three participants.

\section{Instruments and NFB Training}

This study was a pre/posttest repeatedmeasures design where children were enrolled in one of three groups: normally functioning controls (Group A), children with AS with less than four sessions of NFB (Group B), and children with AS with more than 40 sessions of NFB (Group C). This design allowed us to determine the effects of the independent variable (humorous reading materials) on the dependent variable (emotional states/affect in children diagnosed with AS who had received less than four and more than 40 sessions of NFB training and controls).

Reading Materials/Stories. The stories were selected by referencing various titles that researchers had suggested, as well as by asking school board curriculum consultants, teachers, and parents to rate a selection of reading materials. The final set of short stories was taken from Laughs: Funny Stories Selected by Claire MacKay (MacKay, 1997). Each of the 14 stories in this collection were written by various well-known Canadian authors and ranged from five to 28 soft-cover novel pages. Some of the issues in the stories included romantic crushes, friendly and unfriendly 
competition (e.g., sports, auditions), and embarrassing moments, while including a component of humor.

Stories were presented to children on $81 / 2 \times 10^{\prime \prime}$ black-and-white photocopied pages (plain text). Pictures and illustrations were excluded, as Jolley, Zhi, and Thomas (1998) and Cullinan (1989) have found that some types of pictures in children's literature can evoke a stronger (either positive or negative) emotion in children. There was also a possibility that images, colors, pictures, and other materials would impact a child's understanding of the story. Thus, all visual stimuli (e.g., pictures, illustrations) were excluded from all stories.

Multiple Affect Adjective Check List-Revised (MAACL-R). The MAACL-R (Zuckerman \& Lubin, 1985) was used to measure affect before and after reading the humorous stories. The MAACL-R is considered to be a reliable $(\alpha=.70-.91)$ and valid measure of state (e.g., "How you feel now-today") and trait ("How you generally feel") affect-however-only state affect was of interest in this study. This instrument is widespread and popular in studies where emotional level or change in emotion is being measured (Zuckerman \& Lubin, 1985). It has been used in more than 700 studies, with the trait test norm referenced on a sample of almost 1,500 and the state test normed on a sample of 537 (Zuckerman \& Lubin, 1985).

The MAACL-R consists of 132 adjectives that are divided into five subscales: Anxiety, Depression, Hostility, Positive Affect, and Sensation Seeking. Examples of adjectives in the positive affect domain include affectionate, satisfied, joyful, and glad. Adjectives in the depression domain include alone, destroyed, lonely, and grim. Two scores are calculated for each child: positive affect and sensation seeking (PASS) and dysphoria (DYS). Scores for the PASS scale are generated by adding up the scores from the Positive Affect and Sensation Seeking subscales (number of items endorsed), whereas scores for the DYS scale are generated by adding up the scores from the Depression, Hostility, and DYS subscales. Certain adjectives in the Sensation Seeking domain are negatively scored (i.e., subtracted from total). Revisions were made to the scale for use in this study to account for the short period between the administration of the pretest and posttest. One revision was having the 132 adjectives divided into three shorter (condensed) versions of the tests (V1, V2, and V3). To divide the adjectives randomly and effectively into the three versions, the 132 adjectives were divided into their respective domains/factors (Positive Affect, Sensation Seeking, Anxiety, Depression, and Hostility) in alphabetical order. This resulted in 15 adjectives in the Anxiety domain, 27 in Depression, 24 in Hostility, 45 in Positive Affect, and 21 in the Sensation Seeking domain. The adjectives from each domain were then randomly placed into one of three versions of the test (V1, V2, and V3). Each version contained five adjectives for Anxiety, nine for Depression, eight for Hostility, 15 for Positive Affect, and seven for Sensation Seeking - for a total of 44 adjectives on each version.

NFB. NFB training (presented as a computer game) involves placing sensors (electrodes) on the scalp and ear lobe(s) accordingly, which aid in the training of decreasing dominant slow wave activity while increasing fast wave activity. Children diagnosed with AS (like those in this study) are trained to increase SMR while decreasing their slow wave activity (Thompson et al., 2010). For most sessions, the placement of the electrode for monitoring EEG data is at the vertex $(\mathrm{Cz})$ referenced to the right ear lobe with ground on the left ear lobe unless the child has deficit language problems (i.e., verbal or written communication deficits) - in which case it is placed on the left lobe for some sessions (Thompson et al., 2010). These electrodes are attached to a computer to record and register the various frequencies and amplitudes of the brainwaves. Brainwave activity is then converted into a "game-like" display, which provides visual and auditory feedback (i.e., reinforcement) regarding level of concentration (Sears \& Thompson, 1998; Thompson \& Thompson, 1998). In this study, NFB training was done using the Procomp Biograph Infiniti equipment (Thought Technology) 
with a sampling rate of 256 samples per second. Impedances were checked before every training session, and the goal was to have them all below $5 \mathrm{KOhms}$ and within $1 \mathrm{KOhm}$ of each other. All subjects had single-channel QEEG assessments done using the Biograph Infiniti equipment. Initial assessments all met the criterion of impedance below $5 \mathrm{KOhms}$ between each pair of electrodes and all three readings within $1 \mathrm{KOhm}$ of each other. NFB training parameters were set according to EEG findings and involved training at the central location $(\mathrm{Cz})$ that rewarded subjects for inhibiting frequency ranges that were excessively high (such as $3-7 \mathrm{~Hz}$ or $4-8 \mathrm{~Hz}$ ) and rewarding frequencies that were low (such as sensorimotor rhythm in the $12-15 \mathrm{~Hz}$ range). There was always an inhibit on higher frequencies that indicated muscle tension artifacts. If "busy-brain" patterns were noted (spindling beta in frequencies $>20 \mathrm{~Hz}$ ), then rewards were also contingent upon amplitude of the relevant frequencies in the higher beta range being decreased.

Children earned tokens during training, which could be exchanged for prizes (e.g., books, gift cards, pencils, toys). All training sessions were conducted one-on-one with a skilled NFB trainer.

\section{Procedure}

On testing days, the children were given one of three versions of the MAACL-R (random assignment) as a pretest to measure affect. Upon completion of the pretest, the children were presented with all 14 stories selected from MacKay's (1997) book, facedown, and asked to choose one story. They were told that they could choose a short story or a long one depending on how much they wanted to read. In effect, avid readers would have the opportunity to select longer stories, whereas those who were not as keen on reading would have the opportunity to select shorter stories. Each child was told to take their time to read and to think carefully about the story and what the characters were feeling. Each story took about 15 to $25 \mathrm{~min}$ to read. Following the reading session, each child was given a short comprehension test consisting of five questions. This helped ensure that children understood the story they selected. Each of the questions required them to project into the minds of the characters and decipher the emotions experienced by the characters in the story. The responses also required a level of emotional understanding and empathy for the characters. Questionnaires were scored based on the appropriateness of the response and whether or not it was evident that the child comprehended the emotion(s) being evoked by the stories. If test scores failed to meet the minimum requirements $(80 \%$ correct, or four of five correct), the data for those children were omitted from the final data analysis. The final sample $(n=37)$ comprised 23 normally functioning controls (Group A) and 14 children diagnosed with AS (three with less than four NFB sessions and 11 with more than 40 NFB sessions; Groups B and C, respectively).

After completing the comprehension test, each child was asked to complete a different version of the MAACL-R at posttesting to assess how the participants felt immediately after the induction of the experimental condition. For both pre- and posttesting, the children were asked to "check off as many words to describe how you are feeling right now." To ensure comprehension, children were also instructed to ask the experimenter to clarify the meanings of words, if the word was unfamiliar. The experimenter would then provide a definition of the word and use it in a sentence.

Procedures for the children with AS (Groups B and C) differed from that of the controls (Group A) as test administration for the children with AS was done on an individual (one-on-one) basis, versus a group basis for the controls.

\section{RESULTS}

Descriptive statistics for age and gender within each of the three groups are presented in Table 1. The descriptives for Pre- and Post-DYS and PASS scores for each group are presented in Table 2 and plotted in Figures 1, 2, and 3. 
TABLE 1. Descriptive Statistics for Age and Gender by Group Assignment

\begin{tabular}{lllll}
\hline Variable & ${\text { Group A: } \text { Controls }^{a}}$ & Group B: AS, $<4$ NFB $^{b}$ & Group C: AS, $>40$ NFB $^{c}$ & Total \\
\hline Age $(M, S D)$ & $12.44(.51)$ & $12.00(2.00)$ & $11.73(1.62)$ & $12.19(1.01)$ \\
Female & 13 & 1 & 2 & 16 \\
Male & 10 & 2 & 9 & 21 \\
\hline
\end{tabular}

Note. $\mathrm{AS}=$ Asperger's Syndrome; NFB = neurofeedback.

${ }^{a} N=23$.

${ }^{b} \mathrm{~N}=3$.

${ }^{c} N=11$.

A series of paired samples $t$ tests were run to examine the change in DYS and PASS scores after the reading activity for each of the three groups. For Group A (controls), DYS scores decreased significantly after reading the happy stories, $t(22)=2.15, p<.05$, and PASS scores increased significantly, $t(22)=2.80, p<.01$. For Group C (AS, $>40$ NFB), DYS scores also decreased significantly after the happy reading materials, $t(10)=2.35, p<.05$, and whereas PASS also scores increased $(M$ difference $=$ 2.36), the change was not significant $(p=.12)$. No significant change in DYS and PASS scores were found for Group B (AS, <4 NFB) after reading the stories.

To examine within- and between-subjects effects for Groups A and C, a repeatedmeasures analysis of variance (ANOVA) was performed. Due to the small sample size in Group B, it was not included in the repeatedmeasures ANOVA - as there would be low statistical power. For DYS, there was a main effect of time, $F(1,32)=11.09, p<.01$, and a main effect of group, $F(1,32)=11.05$, $p<.01$, but no significant interaction effect. Further supporting the paired samples $t$ test, dysphoria scores decreased significantly for both groups after the reading activity. The normally functioning control group had significantly lower pre- and post-DYS scores compared to the children diagnosed with AS who had received a minimum of 40 NFB training sessions.

For PASS, there was a main effect of time, $F(1,32)=9.84, p<.01$, but no significant main effect of group or Time $\times$ Group interaction effect. As with the paired samples $t$ test, scores for both groups increased significantly after reading the happy stories. Although Group $C$ had higher PASS scores from Group A both before and after the condition, the difference was not significant.

Overall, results for Group C resembled those of Group A. DYS and PASS emotions tend to polarize after the administration of the reading activity condition, indicating that the experimental condition appears to have an effect on emotional states.

Participants in Group B showed a different trend compared to the participants in groups $\mathrm{A}$ and C, where there was an increase at post-DYS and a decrease at post-PASS. However, it is noteworthy to say that scores for pretest and posttest appear quite random in

TABLE 2. Descriptive Statistics for Pre- and Post-DYS and PASS by Group Assignment

\begin{tabular}{lllll}
\hline Variable & ${\text { Group A: } \text { Controls }^{a}}$ & Group B: AS, $<4$ NFB $^{b}$ & Group C: AS, $>40$ NFB $^{c}$ & Total \\
\hline Pre-DYS $(M, S D)$ & $1.30(2.45)$ & $2.00(.00)$ & $4.64(4.78)$ & $2.35(3.51)$ \\
Post-DYS $(M, S D)$ & $0.26(.54)$ & $2.33(1.52)$ & $2.64(2.87)$ & $1.14(1.97)$ \\
Pre-PASS $(M, S D)$ & $3.83(2.82)$ & $8.66(8.08)$ & $3.91(2.59)$ & $4.24(3.48)$ \\
Post-PASS $(M, S D)$ & $5.44(3.05)$ & $6.00(6.24)$ & $6.27(4.86)$ & $5.73(3.82)$ \\
\hline
\end{tabular}

Note. $\mathrm{DYS}=$ dysphoria; $\mathrm{PASS}=$ positive affect and sensation seeking; $\mathrm{NFB}=$ neurofeedback.

${ }^{a} N=23$.

${ }^{b} N=3$.

${ }^{c} N=11$. 


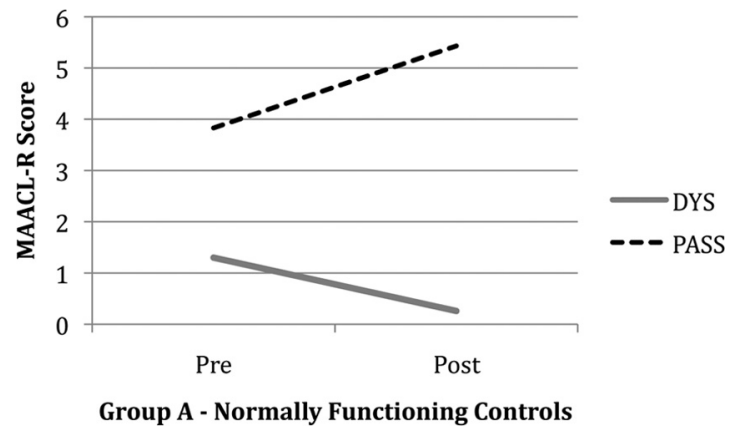

FIGURE 1. Pre- and postdysphoria (DYS) and positive affect/ sensation seeking (PASS) scores for Group A. Note. MAACL$\mathrm{R}=$ Multiple Affect Adjective Check List-Revised.

nature, wherein the three participants in this group tended to show affect states all across the board. For example, the participants would check off adjectives belonging to the depression domain (i.e., tormented, unhappy) yet at the same time check off adjectives belonging to the positive affect domain (i.e., pleased, happy).

The AS participants in Group B continuously made comments about the stories and how improbable and impractical they were. They also noted the (many) ways in which the story was not funny. A disappointing and perhaps negative aspect of the stories is that although the stories dealt with common situations, the students with AS tended to focus intensely on the central negative aspect of the story (such as losing a game or friend), as opposed to focusing on the final successes

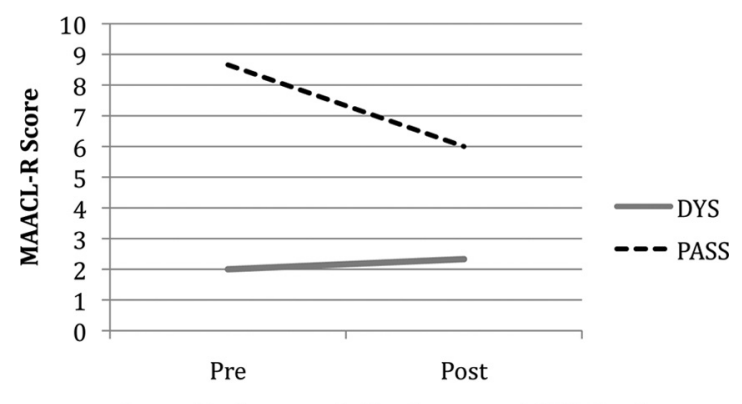

Group B - Asperger's Syndrome, < 4 NFB Sessions

FIGURE 2. Pre- and postdysphoria (DYS) and positive affect/ sensation seeking (PASS) scores for Group B. Note. MAACL$\mathrm{R}=$ Multiple Affect Adjective Check List-Revised; $\mathrm{NFB}=$ neurofeedback.

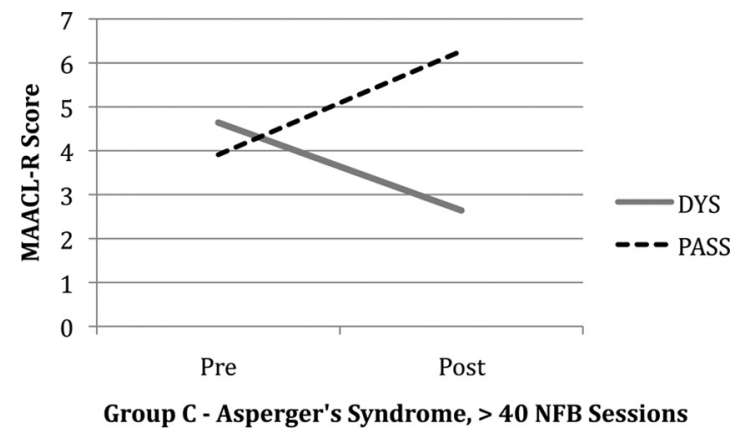

FIGURE 3. Pre- and postdysphoria (DYS) and positive affect/ sensation seeking (PASS) scores for Group C. Note. MAACL$\mathrm{R}=$ Multiple Affect Adjective Check List-Revised; $\mathrm{NFB}=$ neurofeedback.

and/or humorous conclusions of the story, unless pointed out by the experimenter.

\section{DISCUSSION}

Notwithstanding the limited participants in the AS groups and the pilot nature of this project, the findings of the current study prove to be very encouraging in the aid and treatment of children with AS. By assessing the emotions of our participants, we were able to discriminate how children with AS - before and after NFB training - respond to positively toned reading materials. To date, there is little information available on this topic. More specifically, there is little known about the effects of NFB training on individuals with AS and how it aids in emotional understanding of literature. Furthermore, little is known about whether or not emotionally charged text has an influence on the emotions of children with AS. Finally, there are few studies investigating the differences between children with AS and their typically developing peers, as many of the studies investigate only one population, hence providing no means of comparison. The current pilot study contributes to our understanding and begins to address the aforementioned gaps in the research. In addition, it provides practioners, educators, and parents with a tool for inducing positive emotional states in children exhibiting depressive symptoms.

Our results demonstrated significant within- and between-group differences as a 
function of the NFB and the reading activity. As predicted, the normally functioning controls and the children diagnosed with AS who were near completion of their NFB training exhibited a decrease in dysphoria and an increase in positive affect/sensation seeking after reading the happy stories. Essentially, they were less sad and more happy. Worth noting was that prior to the reading activity, the children with AS who had a minimum of 40 NFB sessions displayed higher negative affect compared to positive affect. However, after the activity, their positive affect scores were higher than their dysphoria scores. Furthermore, although the findings also suggest that, even after NFB training, children with AS are still demonstrating more characteristics of depressive symptoms (as measured using the DYS factor) compared with their normally functioning peers, such negative emotions have the ability of being reduced by administering positively toned reading materials. Given that past research has found that individuals with AS tend to show a greater rate of depressive symptoms as compared to typically developing children (Ghaziuddin et al., 1998; Lamarine, 2001; Little, 2001), it is encouraging to know that NFB training could aid in the understanding of positively charged literature, and in turn help alleviate the depressive symptoms.

The finding that Group A (normally functioning controls) and Group $C$ (children with AS after more than 40 sessions of NFB training) would show a more similar pattern of results compared to Group B (AS with less than four sessions of NFB training) was confirmed. This supports previous findings on the "normalizing" effects of NFB training (Monastra, Monastra, \& George, 2002; Ramirez, Desantis, \& Opler, 2001; Schwartz \& Andrasik, 2003; Thompson \& Thompson, 1998). Specifically, NFB can help "normalize" affective, cognitive, and adaptive functioning in individuals with AS. Although there have not been any previous studies addressing emotional understanding in textual information, it was inferred that because NFB training had an effect in socioemotional understanding in nonverbal information, it would also have an effect on socio-emotional understanding of verbal information, as expressed in emotionally charged literature. In essence, the children with AS appear to respond to emotionally charged literature similarly to typically developing children after receiving NFB training. Aside from the other benefits observed after NFB training, it appears to have an effect on children's perception and understanding of emotions in textual information in the absence of visual stimuli (i.e., pictures, colors, photographs).

The children in Group B (those with limited NFB training), on the other hand, did not show such a pattern of change. Alternatively, they tended to show the greatest positive affect/ sensation seeking scores at pretest and a decrease in positive affect at posttest. They also showed an increase in dysphoria at posttest. Their emotional states remained quite random pre- and posttest. Being cautious about generalizing (given the small sample size), one could speculate about this finding. Children with AS before NFB appear to be somewhat deficient in the area of emotional understanding when reading humorous stories. Furthermore, when they were unhappy (which they communicated via conversation and results on the MAACL-R), they tended to focus on the negative aspects of the stories. For example, one participant read a story about being accused of being liar, and continuously informed the experimenter that she or he was once accused of being a liar and was really upset. This participant, however, appeared to have overlooked the humorous and positive conclusion of the short story and focused heavily on the one negative aspect. Such selective recall and mood-congruent learning supports the findings of Riesberg (1997) and Bower et al. (1981), where sad individuals recalled information that was parallel to their current emotional state more so than information that was not parallel. This could be true for children diagnosed with AS prior to NFB training and must be further examined in future studies. Despite the small sample size, however, a common trend in the results of the three participants was evident at all levels of testing. It appears that children with AS without NFB training are not able to 
comprehend or "feel" the emotions the authors of the humorous stories are attempting to evoke and convey, unlike their typically developing children and unlike AS peers who have received more than 40 sessions of NFB training. The use of an NC group (Group A) helped demonstrate that the differences in emotional state scores (as measure by the MAACL-R) may be due to the one difference between Group B and C: the more than 40 sessions of biofeedback training. As previously mentioned, these differences may have occurred by chance, as there were not enough participants to run significant statistical analyses for Group B. Future research with larger sample sizes could investigate whether or not this pattern truly exists, such that emotional states are random after the administration of the experimental condition.

Overall, these findings are promising for using NFB combined with positive literature to decrease depressive symptoms in children diagnosed with AS - especially given the higher than normal rate of depression in these individuals. The current study supports past findings (i.e., mixed results), which maintain various theoretical frameworks regarding emotion, literature, and learning such as the effect of message strength, mood-congruent and incongruent learning, and recall of information (Bower et al., 1981; Ellis et al., 1997; Mitchell et al., 2001; Riesberg, 1997). This awareness, that positively toned reading materials can increase PASS emotional states as well as decrease DYS states, can be applied to classrooms and inside the homes. Educators, parents, librarians, childcare practitioners, and other health care professionals can suggest humorous stories for children who exhibit depressive symptoms.

\section{REFERENCES}

American Psychiatric Association. (1994). Diagnostic and statistical manual of mental disorders (4th ed.). Washington, DC: Author. American Psychiatric Association. (2000). Diagnostic and statistical manual of mental disorders (4th ed., text rev). Washington, DC: Author.
Asperger, H. (1944). Die austistischen psychopathen im kindesalter [Autistic psychopaths in childhood]. Archiv fuer Psychiatrie und Nervenkrankheiten, 117, 76-136.

Asperger, H. (1991). Autistic psychopathy in childhood. In U. Frith (Ed. \& Trans.), Autism and Asperger's syndrome (pp. 37-92). Cambridge, UK: Cambridge University Press.

Attwood, T. (1997). Asperger's syndrome: A guide for parents and professionals. London, UK: Jessica Kingsley.

Attwood, T. (1998). AS: A guide for parents and professionals. London, UK: Jessica Kingsley.

Bower, G. H., Gilligan S. G., \& Monteiro, K. P. (1981). Selectivity of learning caused by affective states. Journal of Experimental Psychology: General, 110, 451-473.

Carpenter, M., Pennington, B. F., \& Rogers, S. J. (2001). Understanding of others' intentions in children with autism. Journal of Autism and Developmental Disorders, 31, 589-599.

Carrington, S., Paoinczak, T., \& Templeton, E. (2003). A phenomenological study: The social world of five adolescents who have Asperger's Syndrome. Australian Journal of Learning Disabilities, 8, 15-21.

Choi, S. W., Chi, S. E., Chung, S. Y., Kim, J. W., Ahn, C. Y., \& Kim, H. T. (2011). Is alpha wave neurofeedback effective with randomized clinical trials in depression? A pilot study. Neuropsychobiology, 63, 43-51.

Coben, R. (2007). Connectivity-guided neurofeedback for Autistic Spectrum Disorder. Biofeedback, 35, 131-135.

Coben, R., \& Myers, T. E. (2010). The relative efficacy of connectivity guided and symptom based EEG biofeedback for autistic disorders. Applied Psychophysiology and Biofeedback, 35(1), 13-23.

Connell, J. P., \& Wellborn, J. G. (1991). Competence, autonomy, and relatedness: A motivational analysis of self-system processes. In M. R. Gunnar \& L. A. Sroufe (Eds.), Self processes and development: The Minnesota symposia on child development (Vol. 23, pp. 43-78). Hillsdale, NJ: Erlbaum. Cullinan, B. E. (1989). Literature and the child (2nd ed.). Orlando, FL: Harcourt Brace Jovanovich. 
de Beus, R. J., \& Kaiser, D. A. (2011). Neurofeedback with children with attention deficit hyperactivity disorder: A randomized doubleblind placebo-controlled study. In R. Coben \& J. R. Evans (Eds.), Neurofeedback and neuromodulation technique and applications (pp. 127-152). New York, NY: Academic Press.

de Niet, P. (2011). The efficacy of LENS neurofeedback treatment for ADHD: A doubleblind, randomized placebo controlled study on adults with $A D H D$. Manuscript submitted for publication. Retrieved from https:// toetsingonline.ccmo.nl/

Durkin, K. (1995). Developmental social psychology: From infancy to old age. Oxford, UK: Blackwell.

Ehlers, S., \& Gillberg, C. (1993). The epidemiology of Asperger's Syndrome. A total population study. Journal of Child Psychology and Psychiatry, 34, 1327-1350.

Ellis, H. C., Ottaway, S. A., Varner, L. J. Becker, A. S. \& Moore, B. A. (1997). Emotion, motivation, and text comprehension: The detection of contradictions in passages. Journal of Experimental Psychology: General, 126, 131-144.

Erdley, C. A., Nangle, D. W., Newman, J. W., \& Carpenter, E. M. (2001). Children's friendship experiences and psychological adjustment: Theory and research. In D. W. Nangle \& C. A. Erdley (Series Eds.) \& W. Damon (Vol. Ed.), New directions for child and adolescent development. The role of friendship in psychological adjustment (Vol. 91, pp. 5-24). San Francisco, CA: JosseyBass.

Fombonne, E., \& Tidmarsh, L. (2003). Epidemiologic data on Asperger disorder. Child and Adolescent Psychiatric Clinics of North America, 12, 15-21.

Gepner, B., Deruelle, C., \& Grynfeltt, S. (2001). Motion and emotion: A novel approach to the study of face processing by young autistic children. Journal of Autism and Developmental Disorders, 31, 37-45.

Ghaziuddin, M., Weidmer-Mikhail, E., \& Ghaziuddin, N. (1998). Comorbidity of Asperger syndrome: A preliminary report.
Journal of Intellectual Disability Research, 42, 279-283.

Green, V. A., Pituch, K. A., Itchon, J., Choi, A., O'Reilly, M., \& Sigafoos, J. (2006). Internet survey of treatments used by parents of children with autism. Research in Developmental Disabilities, 27, 70-84.

Hammer, B. U., Colbert, A. P., Brown, I. A., \& Ilioi, E. C. (2011). Neurofeedback for insomnia: A pilot study of Z-score SMR and individualized protocols. Applied Psychophysiology \& Biofeedback, 36, 251-264.

Hammond, D. C. (2005). Neurofeedback with anxiety and affective disorders. Child \& Adolescent Psychiatric Clinics of North America, 14, 105-123.

Hammond, D. C. (2011). What is neurofeedback: An update. Journal of Neurotherapy, 15, 305-336.

Hedley, D., \& Young, R. (2006). Social comparison processes and depressive symptoms in children and adolescents with Asperger's Syndrome. Autism, 10, 139-153.

Jolley, R. P., Zhi, Z., \& Thomas, G. V. (1998). The development of understanding emotions metaphorically expressed in pictures: A cross-cultural comparison. Journal of Cross-Cultural Psychology, 29, 358-376.

Kaland, N., Moller-Nielsen, A., Smith, L., Mortensen, E. L., Callesen, K., \& Gottlieb, D. (2005). The Strange Stories test: A replication study of children and adolescents with Asperger's Syndrome. European Child \& Adolescent Psychiatry, 14, 73-82.

Kleber, B., Gruzelier, J., Bensch, M., \& Birbaumer, N. (2008). Effects of EEGbiofeedback on professional singing performances. Revista Espanola Psichologica, 10, 77-61.

Knezevic, B., Thompson, L., \& Thompson, M. (2010). Pilot project to ascertain the utility of Tower of London test to assess outcomes of neurofeedback in clients with Asperger's syndrome. Journal of Neurotherapy, 14(3), 3-19.

Kouijzer, E. E. J., van Schie, H. T., de Moor, J. M. H., Gerrits, B. J. L., \& Buitelaar, J. K. (2010). Neurofeedback treatment in autism. Preliminary findings in behavioural, 
cognitive, and neurophysiological functioning. Research in Autism Spectrum Disorders, 4, 386-399.

Lamarine, R. J. (2001). Asperger syndrome: Advice for school personnel. Preventing School Failure, 45, 148-153.

Laurent, A. C., \& Rubin, E. (2004). Challenges in emotional regulation in Asperger's Syndrome and high-functioning autism. Topics in Language Disorders, 24, 286-297.

Levesque, J., Beauregard, M., \& Mensour, B. (2006). Effect of neurofeedback training on the neural substrates of selective attention in children with attention-deficit/hyperactivity disorder: A functional magnetic resonance imaging study. Neuroscience Letters, 394, 216-221.

Little, L. (2001). Peer victimization of children with Asperger Spectrum disorder [Letter to the Editor]. Journal of the American Academic Child and Adolescent Psychiatry, 40, 995-996.

Lubar, J. F. (1995). Neurofeedback for the management of attention deficit/hyperactivity disorders. In M. S. Schwartz (Ed.), Biofeedback: A practitioner's guide (pp. 493-522). New York, NY: Guilford.

MacKay, C. (1997). Laughs: Funny stories selected by Claire MacKay. Toronto, Canada: Tundra Books.

Mayes, S. D., \& Calhoun, S. (2008). WISC-IV and WIAT-II profiles in children with high-functioning autism. Journal of Autism and Developmental Disorders, 38, 428-439.

Mitchell, M. M., Brown, K. M., MorrisVillagran, M., \& Villagran, P. D. (2001). The effects of anger, sadness and happiness on persuasive message processing: A test of the negative state relief model. Communication Monographs, 68, 347-359.

Monastra, V. J., Monastra. D. M., \& George, S. (2002). The effects of stimulant therapy, EEG biofeedback, and parenting style on the primary symptoms of attention-deficit/ hyperactivity disorder. Applied Psychophysiology and Biofeedback, 27, 231-249.

Nangle, D. W., \& Erdley, C. A. (2001). Editors' notes. In D. W. Nangle \& C. A. Erdley (Series Eds.) \& W. Damon (Vol. Ed.), New directions for child and adolescent development. The role of friendship in psychological adjustment (Vol. 91, pp. 1-4). San Francisco, CA: Jossey-Bass.

Oberle, E., Schonert-Reichl, K., \& Thomson, K. (2010). Understanding the link between social and emotional well-being and peer relations in early adolescence: Genderspecific predictors of peer acceptance. Journal of Youth and Adolescence, 39, 1330-1342.

Parker, T. S. (2004). Changing emotion: The use of therapeutic stories. Available from ProQuest database. (AAI3108721)

Portway, S. M., \& Johnson, B. (2005). Do you know I have Asperger's syndrome? Risks of non-obvious disability. Health, Risk \& Society, 7, 73-83.

Ramirez, P. M., Desantis, D., \& Opler, L. A. (2001). EEG biofeedback treatment of ADD: A viable alternative to traditional medical intervention? Annals of the New York Academy of Sciences, 931, 342-358.

Reid, A. (2005, September). Autistic spectrum disorders, assessment and intervention results after neurofeedback in 146 cases. Student award presentation, International Society for Neuronal Regulation annual meeting, Denver, CO.

Reisberg, D. (1997). Cognition: Exploring the science of the mind. New York, NY: Norton.

Rosenn, D. W. (1999). What is Asperger's disorder? Boston, MA: President and Fellows of Harvard College.

Rubin, K. H., Dwyer, K. M., Booth-LaForce, C., Kim, A. H., Burgess, K. B., \& Rose-Krasnor, L. (2004). Attachment, friendship, and psychological functioning in early adolescence. Journal of Early Adolescence, 24, 326-356.

Schwartz. M. S., \& Andrasik, F. (2003). Biofeedback: A practitioner's guide (3rd ed.). New York, NY: Guilford.

Sears, W., \& Thompson, L. (1998). The A.D.D. book: New understandings, new approaches to parenting your child. New York, NY: Little, Brown.

Smith Myles, B., Hilgenfeld, T. D., Barnhill, G. P., Griswold, D. E., Hagiwara, T. \& Simpson, R. L. (2002). Analysis of reading skills in individual 
with Asperger syndrome. Focus on Autism and Other Developmental Disabilities, 17, 44-48.

Smith Myles, B., \& Simpson, R. L. (2001). Effective practises for students with Asperger Syndrome. Focus on Exceptional Children, 34, pp. 1-14.

Thompson, L., \& Thompson, M. (1998). Neurofeedback combined with training in metacognitive strategies: Effectiveness in students with ADD. Applied Psychophysiology and Biofeedback, 23, 243-263.

Thompson, L., \& Thompson, M. (2007). Neurofeedback for stress management. In P. Lerner, R. Woolfolk, \& W. Sime (Eds.), Principles, practice of stress management (3rd ed., pp. 249-287). New York, NY: Guilford.

Thompson, L., Thompson, M., \& Reid, A. (2010). Neurofeedback outcomes in clients with Asperger's Syndrome. Applied Psychophysiology and Biofeedback, 35, 63-81.

Thornton, K. E., \& Carmody, D. P. (2005). Electroencephalogram biofeedback for reading disability and traumatic brain injury. Child
\& Adolescent Psychiatric Clinics of North America, 14, 137-162.

Walker, J. E., \& Norman, C. A. (2006). The neurophysiology of dyslexia: A selective review with implications for neurofeedback remediation and results of treatment in twelve consecutive cases. Journal of Neurotherapy, 10, 45-55.

Wentzel, K. R. (2009). Peers and academic functioning at school. In K. H. Rubin, W. M. Bukowski, \& B. Laursen (Eds.), Handbook of peer interactions, relationships, and groups (pp. 531-547). New York, NY: Guilford.

Wing, L. (1981). Asperger's syndrome: A clinical account. Psychological Medicine, 11, 115-129.

World Health Organization. (1994). International classification of diseases. (10th ed.). Geneva, Switzerland: Author.

Zuckerman, M., \& Lubin, B. (1985). Manual for the MAACL-R: The Multiple Affect Adjective Check List-Revised. San Diego, CA: Educational and Industrial Testing Service. 